\title{
Complete genome sequence of the aquatic bacterium Runella slithyformis type strain (LSU $4^{\mathrm{T}}$ )
}

\author{
Alex Copeland', Xiaojing Zhang ${ }^{1,2}$, Monica Misra ${ }^{1,2}$, Alla Lapidus ${ }^{1}$, Matt Nolan', Susan \\ Lucas $^{1}$, Shweta Deshpande ${ }^{1}$, Jan-Fang Cheng ${ }^{1}$, Roxanne Tapia ${ }^{1,2}$, Lynne A. Goodwin ${ }^{1,2}$, Sam \\ Pitluck ${ }^{1}$, Konstantinos Liolios ${ }^{1}$, Ioanna Pagani ${ }^{1}$, Natalia Ivanova ${ }^{1}$, Natalia Mikhailova ${ }^{1}$, \\ Amrita Pati ${ }^{1}$, Amy Chen ${ }^{3}$, Krishna Palaniappan ${ }^{3}$, Miriam Land ${ }^{1,4}$, Loren Hauser ${ }^{1,4}$, Chongle \\ Pan $^{1,4}$, Cynthia D. Jeffries ${ }^{1,4}$, John C. Detter ${ }^{1}$, Evelyne-Marie Brambilla ${ }^{5}$, Manfred Rohde ${ }^{6}$, \\ Olivier D. Ngatchou Djao ${ }^{6}$, Markus Göker ${ }^{5}$, Johannes Sikorski ${ }^{5}$, Brian J. Tindall ${ }^{5}$, Tanja \\ Woyke $^{1}$, James Bristow ${ }^{1}$, Jonathan A. Eisen ${ }^{1,7}$, Victor Markowitz ${ }^{3}$, Philip Hugenholtz ${ }^{1,8}$, \\ Nikos C. Kyrpides ${ }^{1}$, Hans-Peter Klenk ${ }^{5 *}$, and Konstantinos Mavromatis ${ }^{1}$ \\ ${ }^{1}$ DOE Joint Genome Institute, Walnut Creek, California, USA \\ ${ }^{2}$ Los Alamos National Laboratory, Bioscience Division, Los Alamos, New Mexico, USA \\ ${ }^{3}$ Biological Data Management and Technology Center, Lawrence Berkeley National \\ Laboratory, Berkeley, California, USA \\ ${ }^{4}$ Oak Ridge National Laboratory, Oak Ridge, Tennessee, USA \\ ${ }^{5}$ Leibniz Institute DSMZ - German Collection of Microorganisms and Cell Cultures, \\ Braunschweig, Germany \\ ${ }^{6} \mathrm{HZI}$ - Helmholtz Centre for Infection Research, Braunschweig, Germany \\ ${ }^{7}$ University of California Davis Genome Center, Davis, California, USA \\ ${ }^{8}$ Australian Centre for Ecogenomics, School of Chemistry and Molecular Biosciences, The \\ University of Queensland, Brisbane, Australia
}

*Corresponding author: Hans-Peter Klenk

Keywords: strictly aerobic, non-motile, Gram-negative, psychrotolerant, chemoorganotrophic, Cytophagaceae, Cytophagia, GEBA

Runella slithyformis Larkin and Williams 1978 is the type species of the genus Runella, which belongs to the Cytophagaceae, a family that was only recently classified to the order Cytophagales in the class Cytophagia. The species is of interest because it is able to grow at temperatures as low as $4^{\circ} \mathrm{C}$. This is the first completed genome sequence of a member of the genus Runella and the sixth sequence from the family Cytophagaceae. The 6,919,729 bp long genome consists of a $6.6 \mathrm{Mbp}$ circular genome and five circular plasmids of 38.8 to $107.0 \mathrm{kbp}$ length, harboring a total of 5,974 protein-coding and 51 RNA genes and is a part of the Genomic Encyclopedia of Bacteria and Archaea project.

\section{Introduction}

Strain LSU 4T $(=$ DSM $19594=$ ATCC $29530=$ NCIMB 11436) is the type strain of the species Runella slithyformis, which is the type species of its genus Runella [1,2]. The genus currently consists of four validly named species [3]. The genus name is derived from 'rune', a runic letter and the Latin diminutive ending 'ella', yielding the Neo-Latin word 'Runella', meaning 'that which resembles figures of the runic alphabet' [3]. The species epithet is derived from slithy, a nonsense word from Lewis Carroll's Jabberwocky for a fictional organism that is 'slithy' and the Latin word 'suffix' meaning '-like, in the shape of', yielding the Neo-Latin word 'slithyformis' meaning 'slithy in form' [3]. $R$. slithyformis strain LSU $4^{\mathrm{T}}$ was isolated from University Lake near Baton Rouge, Louisiana, USA, and described by Larkin and Williams in 1978 [1]. Another strain of $R$. slithyformis, termed strain 6, was isolated from Elbow Bayou near Baton Rouge [1]. Members of the genus Runella colonize diverse environmental habitats, preferentially aquatic ecosystems, including water bodies in Baton Rouge [1], a wastewater treatment plant in South-Korea [4], environmental water samples and their biofilms in 
Japan [5], and an activated sludge process involved in enhanced biological removal of phosphor in Korea [6]. Another species of this genus was also isolated from the stems of surface-sterilized maize [7]. Here we present a summary classification and a set of features for R. slithyformis strain LSU $4^{\mathrm{T}}$, together with the description of the complete finished genome sequencing and annotation.

\section{Classification and features}

A representative genomic 16S rRNA sequence of $R$. slithyformis LSU $4^{\mathrm{T}}$ was compared using NCBI BLAST $[8,9]$ under default settings (e.g., considering only the high-scoring segment pairs (HSPs) from the best 250 hits) with the most recent release of the Greengenes database [10] and the relative frequencies of taxa and keywords (reduced to their stem [11]) were determined, weighted by BLAST scores. The most frequently occurring genera were Runella (31.0\%), Dyadobacter (30.3\%), Cytophaga (13.7\%), Cyclobacterium (7.5\%) and Algoriphagus (4.0\%) (51 hits in total). Regarding the single hit to sequences from members of the species, the average identity within HSPs was 99.2\%, whereas the average coverage by HSPs was $96.9 \%$. Regarding the two hits to sequences from other members of the genus, the average identity within HSPs was 95.0\%, whereas the average coverage by HSPs was $91.1 \%$. Among all other species, the one yielding the highest score was $R$ zeae (NR_025004), which corresponded to an identity of $95.0 \%$ and an HSP coverage of $91.1 \%$. (Note that the Greengenes database uses the INSDC (= EMBL/NCBI/DDBJ) annotation, which is not an authoritative source for nomenclature or classification.) The highest-scoring environmental sequence was GQ480089 ('changes during sewage treated process activated sludge wastewater treatment plant clone BXHB50'), which showed an identity of $96.6 \%$ and an HSP coverage of $98.0 \%$. The most frequently occurring keywords within the labels of all environmental samples which yielded hits were 'skin' (5.5\%), 'soil' (2.1\%), 'sludg' (2.0\%), 'biofilm' $(1.7 \%)$ and 'forearm, volar' (1.7\%) (199 hits in total). While few of these keywords fit the aquatic and sludge environments from which strain LSU $4^{\mathrm{T}}$ originated, the majority of the hits point to human and even soil, which were, until now, not considered as habitats for R. slithyformis. However, environmental samples which yielded hits of a higher score than the highest scoring species were not found.
Figure 1 shows the phylogenetic neighborhood of $R$. slithyformis LSU $4^{\mathrm{T}}$ in a $16 \mathrm{~S}$ rRNA based tree. The sequences of the two identical 16S rRNA gene copies in the genome do not differ from the previously published 16S rRNA sequence (M62786), which contains 13 ambiguous base calls.

The cells of strain LSU $4^{\mathrm{T}}$ are generally curved rods, with the degree of curvature of individual cells within a culture varying from nearly straight to crescent shape. Cell diameter varies from 0.5 to $0.9 \mu \mathrm{m}$, and the length from 2.0 to $3.0 \mu \mathrm{m}$ [1]. With its curved rod shape, strain LSU $4^{\mathrm{T}}$ differs from other members of the genus, such as $R$. limosa which has long rods while $R$. zeae is bent rodshaped [6]. On the MS agar medium used at the time of isolation, $R$. slithyformis rarely formed long spirals. However, Chelius and Triplett [23] reported the formation of long spirals by the strain LSU $4^{\mathrm{T}}$ when cells were allowed to grow in R2A broth medium (see Figure 2). Larkin and Williams [1] reported a possible production of filaments up to $14 \mu \mathrm{m}$ in length, which are not coiled. This contrasts the findings of Chelius et al. [7] who described the cells of the strain LSU $4^{\mathrm{T}}$ as circular with swollen ends that would not form filaments. Rings with an outer diameter of 2.0 to $3.0 \mu \mathrm{m}$ may also occur [1]. Colonies produced a pale pink, nondiffusible, nonfluorescent pigment on MS agar [1]. The strain LSU $4^{\mathrm{T}}$ is a Gram-negative bacterium (Table 1). Strain LSU 4T is non-motile, aerobic and chemoorganotrophic [1]. It does not grow on media with $\mathrm{NaCl}$ concentrations of $1.5 \%$ or higher [23]. This feature was similar to that of another member of this genus, $R$. zeae [7]. The temperature range for growth is between $4{ }^{\circ} \mathrm{C}-37^{\circ} \mathrm{C}$, with an optimum between $20^{\circ} \mathrm{C}-30^{\circ} \mathrm{C}$ [6]; the strain being unable to grow at temperatures above $37^{\circ} \mathrm{C}$ [23]. The sole carbon sources used by the strain LSU $4^{\mathrm{T}}$ for growth on MS agar are glycogen, D-arabitol, dulcitol, inositol, mannitol, sorbitol and sorbose, but the growth was weak except in the presence of glycogen [23]. Some of these features are however contradictory to the findings of Chelius et al. [7] whose attempt to grow the strain LSU $4^{\mathrm{T}}$ in the presence of glycogen in R2A medium was unsuccessful. Further detailed physiological insight, e.g., carbon source utilization in R2A medium, MS agar medium, or by the API 50 $\mathrm{CH}$ test, have been reported previously $[7,23]$. Also, resistance to a variety of antibiotics has been reported $[7,23]$. 


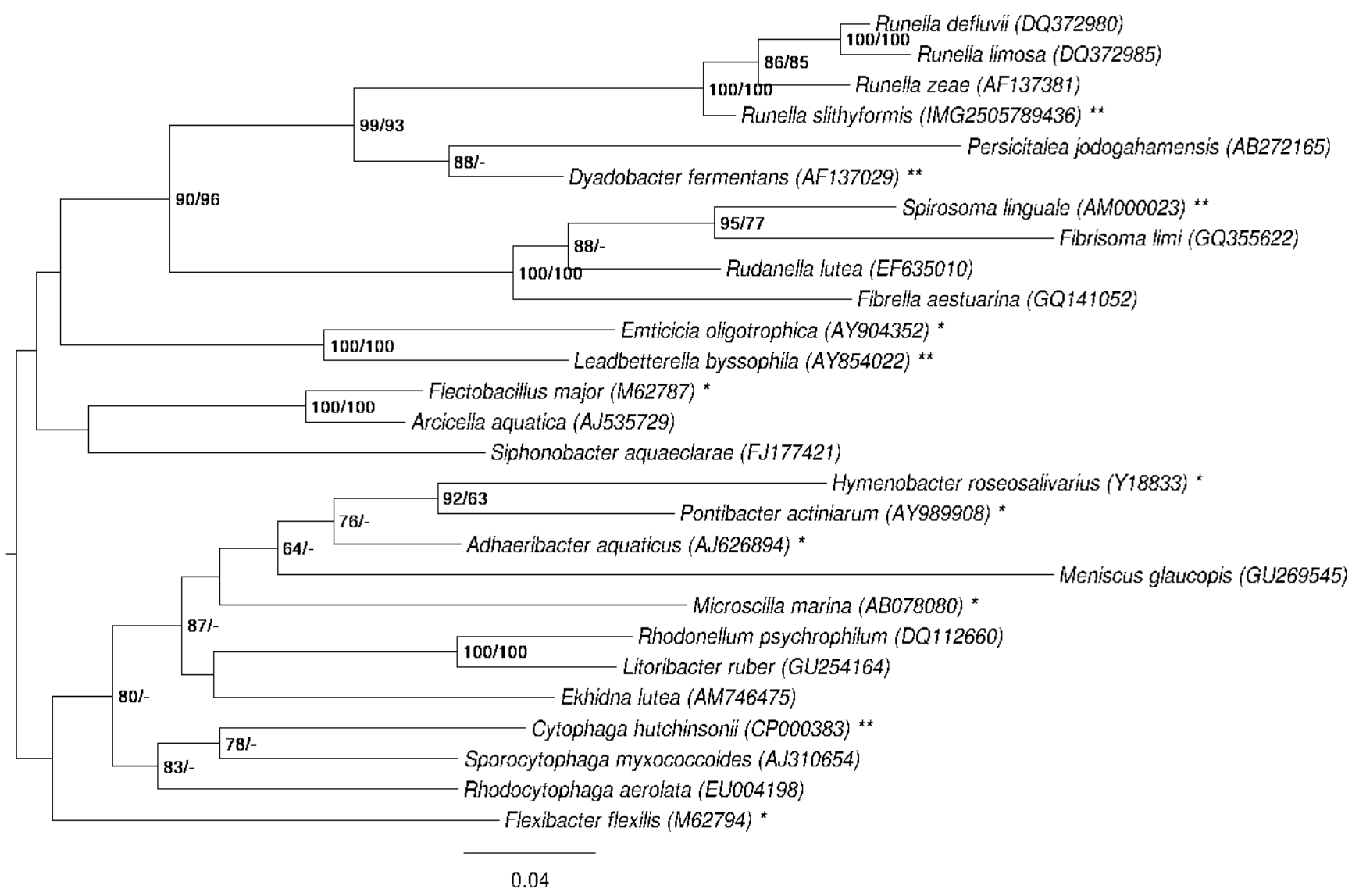

Figure 1. Phylogenetic tree highlighting the position of $R$. slithyformis relative to the type strains of the type species of the other genera within the family Cytophagaceae. The tree was inferred from 1,330 aligned characters [12,13] of the 16S rRNA gene sequence under the maximum likelihood (ML) criterion [14]. Rooting was done initially using the midpoint method [15] and then checked for its agreement with the current classification (Table 1). The branches are scaled in terms of the expected number of substitutions per site. Numbers adjacent to the branches are support values from $400 \mathrm{ML}$ bootstrap replicates [16] (left) and from 1,000 maximum parsimony bootstrap replicates [17] (right) if larger than $60 \%$. Lineages with type strain genome sequencing projects registered in GOLD [18] are labeled with one asterisk, those also listed as 'Complete and Published' with two asterisks [19-22].

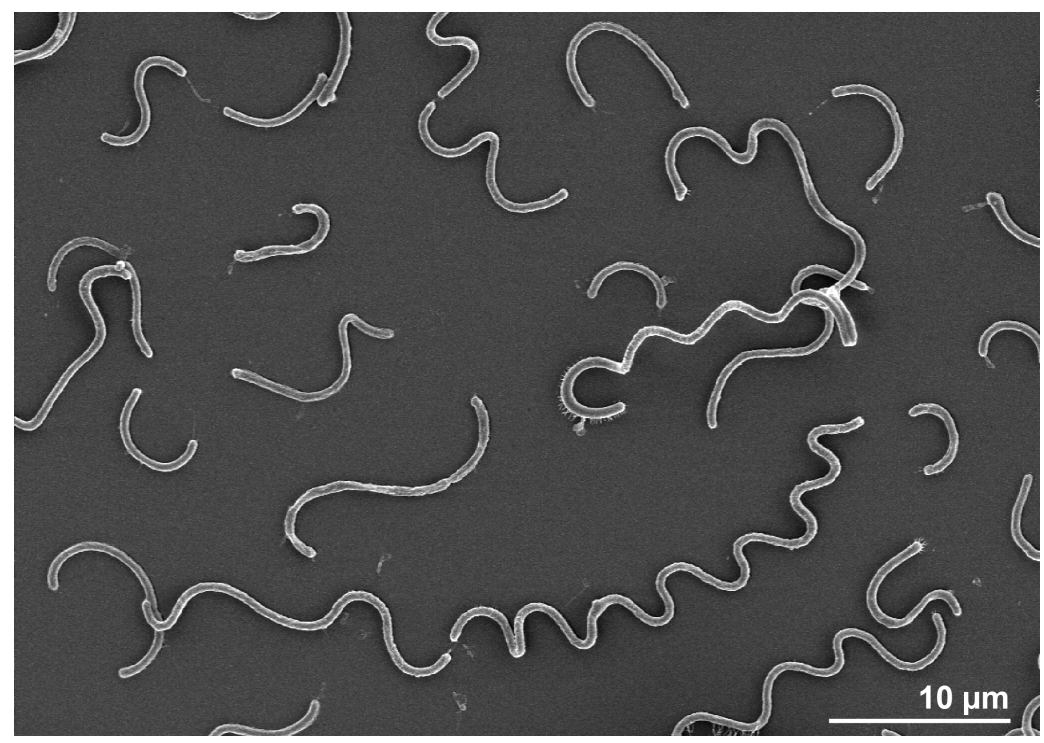

Figure 2. Scanning electron micrograph of $R$. slithyformis $L S U 4^{\top}$ 


\section{Chemotaxonomy}

The principal cellular fatty acids of strain LSU $4^{\mathrm{T}}$ are iso- $\mathrm{C}_{15: 0} \quad$ 2-0 $/ \mathrm{C}_{16: 1} \omega 7 \mathrm{c} \quad$ (32.1\%), iso- $\mathrm{C}_{15: 0}$ (19.8\%) and $\mathrm{C}_{16: 1} \omega 5 \mathrm{c}(16.5 \%)$ [23]. Minor fatty acids include $\mathrm{C}_{16: 0}$ (7.1\%), iso- $\mathrm{C}_{17: 0}$ 3-он $(7.0 \%)$, anteiso- $\mathrm{C}_{15: 0}(4.3 \%)$, iso- $\mathrm{C}_{15: 0}$ 3-0 $(4.1 \%)$, iso- $\mathrm{C}_{15: 1} \mathrm{G}$ (2.4\%), $\mathrm{C}_{16: 0}$ 3-он $(2.0 \%)$, an unknown one (ECL
13.6) (1.83\%) and $\mathrm{C}_{15: 0}(1.5 \%)$ [23]. Major polar lipids were not reported for strain LSU $4^{\mathrm{T}}$, but those of the genus Runella could be retrieved from $R$. defluvii strain $\mathrm{EMB}^{\mathrm{T}} \mathrm{3}^{\mathrm{T}}$ and $R$. limosa strain EMB111 $[4,6]$.

Table 1. Classification and general features of R. slithyformis LSU $4^{\top}$ according to the MIGS recommendations [24].

\begin{tabular}{|c|c|c|c|}
\hline MIGS ID & Property & Term & Evidence code \\
\hline \multirow{13}{*}{ MIGS-7 } & \multirow{8}{*}{ Current classification } & Domain Bacteria & TAS [25] \\
\hline & & Phylum Bacteroidetes & TAS $[26,27]$ \\
\hline & & Class Cytophagia & TAS $[27,28]$ \\
\hline & & Order Cytophagales & TAS $[2,29]$ \\
\hline & & Family Cytophagaceae & TAS $[2,30]$ \\
\hline & & Genus Runella & TAS $[1,2]$ \\
\hline & & Species Runella slithyformis & TAS $[1,2]$ \\
\hline & & Type strain LSU $4^{\top}$ & TAS $[1,2]$ \\
\hline & Gram stain & negative & TAS [1] \\
\hline & Cell shape & curved rod-shaped, rigid & TAS [1] \\
\hline & Motility & non-motile & TAS [1] \\
\hline & Sporulation & none & TAS [1] \\
\hline & Temperature range & $\begin{array}{l}\text { psychrotolerant mesophiles, grows at } \\
\text { temperatures as low as } 4^{\circ} \mathrm{C}\end{array}$ & TAS [23] \\
\hline \multirow{5}{*}{ MIGS-22 } & Optimum temperature & $20^{\circ} \mathrm{C}-30^{\circ} \mathrm{C}$ & TAS [6] \\
\hline & Salinity & no growth in the presence of $\mathrm{NaCl}(1.5 \%)$ & TAS [31] \\
\hline & Relationship to oxygen & strictly aerobic & TAS [1] \\
\hline & Carbon source & carbohydrates & TAS $[1,23]$ \\
\hline & Energy metabolism & chemoorganotroph & TAS [1] \\
\hline MIGS-6 & Habitat & fresh water & TAS [1] \\
\hline MIGS-15 & Biotic relationship & free living & NAS \\
\hline MIGS-14 & Known pathogenicity & none & NAS \\
\hline \multirow[t]{2}{*}{ MIGS-16 } & Specific host & none & NAS \\
\hline & Biosafety level & 1 & TAS [32] \\
\hline MIGS-23.1 & Isolation & fresh water lake & TAS [1] \\
\hline MIGS-4 & Geographic location & University Lake, Baton Rouge, Louisiana, USA & TAS [1] \\
\hline MIGS-5 & Time of sample collection & 1978 or before & TAS [1] \\
\hline MIGS-4.1 & Latitude & 30.417 & NAS \\
\hline MIGS-4.2 & Longitude & -91.167 & NAS \\
\hline MIGS-4.3 & Depth & not reported & \\
\hline MIGS-4.4 & Altitude & $15 \mathrm{~m}$ & NAS \\
\hline
\end{tabular}

Evidence codes - IDA: Inferred from Direct Assay (first time in publication); TAS: Traceable Author Statement (i.e., a direct report exists in the literature); NAS: Non-traceable Author Statement (i.e., not directly observed for the living, isolated sample, but based on a generally accepted property for the species, or anecdotal evidence). These evidence codes are from the Gene Ontology project. If the evidence code is IDA, then the property was directly observed for a living isolate by one of the authors or an expert mentioned in the acknowledgements [33]. 


\section{Genome sequencing and annotation \\ Genome project history}

This organism was selected for sequencing on the basis of its phylogenetic position [34], and is part of the Genomic Encyclopedia of Bacteria and Archaea project [35]. The genome project is deposited in the Genomes On Line Database [18] and the complete genome sequence is deposited in GenBank. Sequencing, finishing and annotation were performed by the DOE Joint Genome Institute (JGI). A summary of the project information is shown in Table 2.

Table 2. Genome sequencing project information

\begin{tabular}{|c|c|c|}
\hline MIGS ID & Property & Term \\
\hline MIGS-31 & Finishing quality & Finished \\
\hline MIGS-28 & Libraries used & $\begin{array}{l}\text { Four genomic libraries: one } 454 \text { pyrosequence standard library, } \\
\text { two } 454 \text { PE libraries ( } 2 \mathrm{~kb} \text { and } 11 \mathrm{~kb} \text { insert sizes), one Illumina } \\
\text { library }\end{array}$ \\
\hline MIGS-29 & Sequencing platforms & Illumina GAii, 454 GS FLX Titanium \\
\hline MIGS-31.2 & Sequencing coverage & $100.4 \times$ Illumina; $28.2 \times$ pyrosequence \\
\hline MIGS-30 & Assemblers & Newbler version 2.3, Velvet 0.7.63, phrap version SPS - 4.24 \\
\hline \multirow[t]{6}{*}{ MIGS-32 } & Gene calling method & Prodigal 1.4, GenePRIMP \\
\hline & INSDC ID & $\begin{array}{l}\text { CP002859 (chromosome) } \\
\text { CP002860-64 (plasmids RUNSL01-05) }\end{array}$ \\
\hline & Genbank Date of Release & August 16, 2011 \\
\hline & GOLD ID & Gc01829 \\
\hline & NCBI project ID & 49125 \\
\hline & Database: IMG-GEBA & 2505679030 \\
\hline \multirow[t]{2}{*}{ MIGS-13 } & Source material identifier & DSM 19594 \\
\hline & Project relevance & Tree of Life, GEBA \\
\hline
\end{tabular}

\section{Growth conditions and DNA isolation}

R. slithyformis strain LSU 4T, DSM 19594, was grown in DSMZ medium 7 (AncyclobacterSpirosoma medium) [36] at $28^{\circ} \mathrm{C}$. DNA was isolated from 0.5-1 g of cell paste using MasterPure Gram-positive DNA purification kit (Epicentre MGP04100) following the standard protocol as recommended by the manufacturer with modification st/DL for cell lysis as described in $\mathrm{Wu}$ et al. 2009 [35]. DNA is available through the DNA Bank Network [31].

\section{Genome sequencing and assembly}

The genome was sequenced using a combination of Illumina and 454 sequencing platforms. All general aspects of library construction and sequencing can be found at the JGI website [37]. Pyrosequencing reads were assembled using the Newbler assembler (Roche). The initial Newbler assembly consisting of 121 contigs in two scaffolds was converted into a phrap [38] assembly by making fake reads from the consensus, to collect the read pairs in the 454 paired end library. Illumina GAii sequencing data (638.9 Mb) was assembled with Velvet [39] and the consensus sequences were shredded into $2.0 \mathrm{~kb}$ overlapped fake reads and assembled together with the 454 data. The $454 \mathrm{draft}$ assembly was based on 206.2 $\mathrm{Mb} 454$ draft data and all of the 454 paired end data. Newbler parameters are -consed -a 50 -1 350 -g -m -ml 20. The Phred/Phrap/Consed software package [38] was used for sequence assembly and quality assessment in the subsequent finishing process. After the shotgun stage, reads were assembled with parallel phrap (High Performance Software, LLC). Possible mis-assemblies were corrected with gapResolution [37], Dupfinisher [40], or sequencing cloned bridging PCR fragments with subcloning. Gaps between contigs were closed by editing in Consed, by PCR and by Bubble PCR primer walks (J.-F. Chang, unpublished). A total of 289 additional reactions and 3 shatter libraries 
were necessary to close gaps and to raise the quality of the finished sequence. Illumina reads were also used to correct potential base errors and increase consensus quality using a software Polisher developed at JGI [41]. The error rate of the completed genome sequence is less than 1 in 100,000. Together, the combination of the Illumina and 454 sequencing platforms provided $128.6 \times$ coverage of the genome. The final assembly contained 540,807 pyrosequence and 19,068,176 Illumina reads.

\section{Genome annotation}

Genes were identified using Prodigal [42] as part of the Oak Ridge National Laboratory genome annotation pipeline, followed by a round of manual curation using the JGI GenePRIMP pipeline [43]. The predicted CDSs were translated and used to search the National Center for Biotechnology Information (NCBI) nonredundant database,
UniProt, TIGR-Fam, Pfam, PRIAM, KEGG, COG, and InterPro databases. Additional gene prediction analysis and functional annotation was performed within the Integrated Microbial Genomes - Expert Review (IMG-ER) platform [44].

\section{Genome properties}

The genome consists of one circular chromosome with a length of $6,568,739 \mathrm{bp}$ and a $\mathrm{G}+\mathrm{C}$ content of $47 \%$, and five circular plasmids with $38,784 \mathrm{bp}$, $44,754 \mathrm{bp}, 66,926 \mathrm{bp}, 93,527 \mathrm{bp}$ and $106,999 \mathrm{bp}$ length, respectively (Table 3 and Figure 3 ). Of the 6,025 genes predicted, 5,974 were protein-coding genes, and 51 RNAs; 182 pseudogenes were also identified. The majority of the protein-coding genes $(59.7 \%)$ were assigned a putative function while the remaining ones were annotated as hypothetical proteins. The distribution of genes into COGs functional categories is presented in Table 4.

Table 3. Genome Statistics

\begin{tabular}{lrr}
\hline Attribute & Value & \% of Total \\
\hline Genome size (bp) & $6,919,729$ & $100.00 \%$ \\
DNA coding region (bp) & $6,063,039$ & $87.62 \%$ \\
DNA G+C content (bp) & $3,212,364$ & $46.42 \%$ \\
Number of replicons & 6 & \\
Extrachromosomal elements & 5 & \\
Total genes & 6,025 & $100.00 \%$ \\
RNA genes & 51 & $0.85 \%$ \\
rRNA operons & 2 & \\
tRNA genes & 43 & $0.71 \%$ \\
Protein-coding genes & 5,974 & $99.15 \%$ \\
Pseudo genes & 182 & $3.02 \%$ \\
Genes with function prediction & 3,599 & $59.73 \%$ \\
Genes in paralog clusters & 3,238 & $53.74 \%$ \\
Genes assigned to COGs & 3,912 & $64.93 \%$ \\
Genes assigned Pfam domains & 4,008 & $66.52 \%$ \\
Genes with signal peptides & 1,748 & $29.01 \%$ \\
Genes with transmembrane helices & 1,350 & $22.41 \%$ \\
CRISPR repeats & 0 & \\
\hline
\end{tabular}




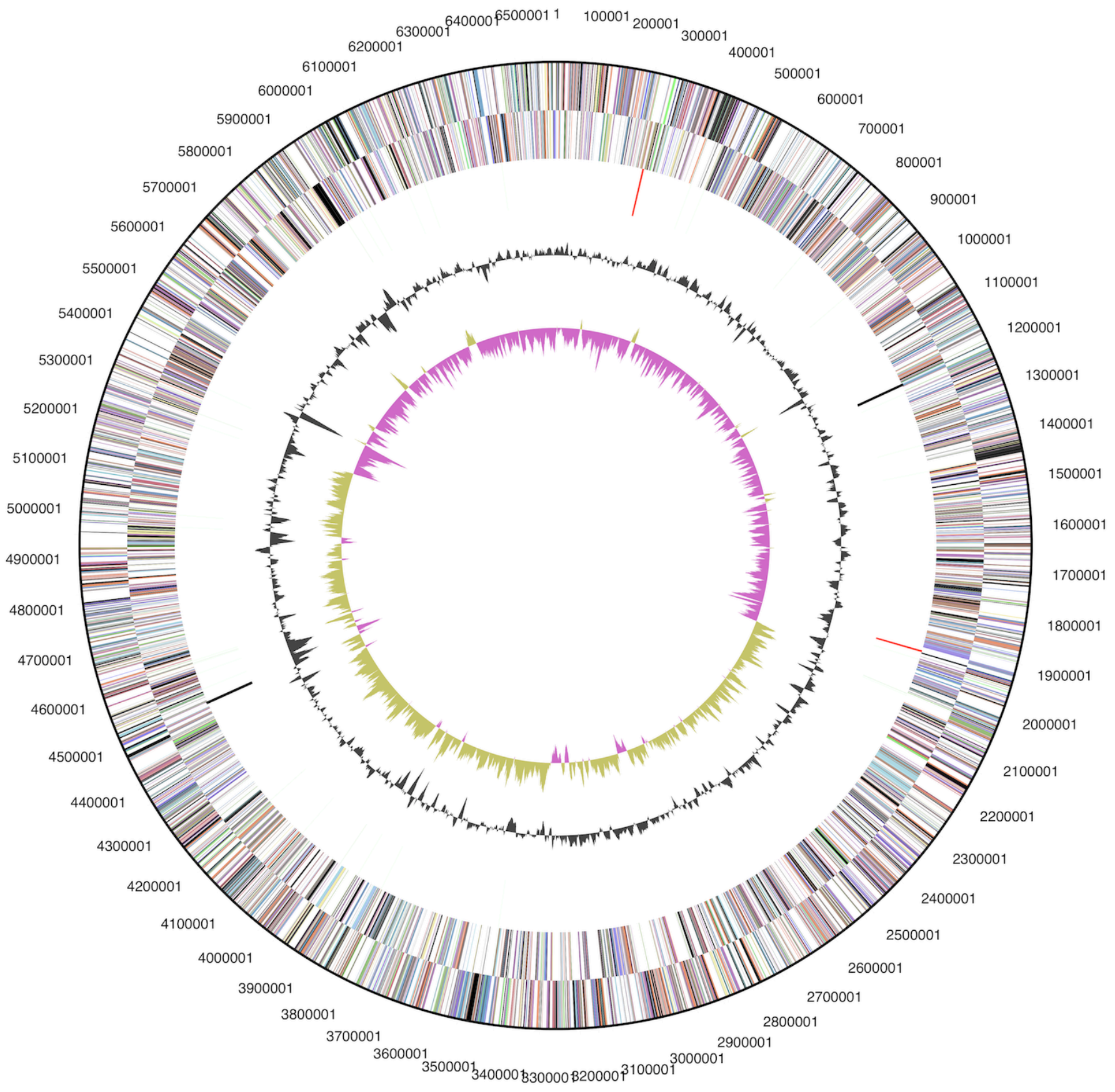

Figure 3. Graphical map of the circular chromosome (plasmids not shown, but accessible through the img/er pages on the JGI web pages [37]). From outside to center: Genes on forward strand (color by COG categories), Genes on reverse strand (color by COG categories), RNA genes (tRNAs green, rRNAs red, other RNAs black), GC content, GC skew. 
Table 4. Number of genes associated with the general COG functional categories

\begin{tabular}{crrl}
\hline Code & value & \%age & Description \\
\hline J & 173 & 4.0 & Translation, ribosomal structure and biogenesis \\
A & 0 & 0.0 & RNA processing and modification \\
K & 338 & 7.8 & Transcription \\
L & 216 & 5.0 & Replication, recombination and repair \\
B & 1 & 0.2 & Chromatin structure and dynamics \\
D & 36 & 0.8 & Cell cycle control, cell division, chromosome partitioning \\
Y & 0 & 0.0 & Nuclear structure \\
V & 126 & 2.9 & Defense mechanisms \\
T & 272 & 6.3 & Signal transduction mechanisms \\
M & 372 & 8.6 & Cell wall/membrane/envelope biogenesis \\
N & 14 & 0.3 & Cell motility \\
Z & 1 & 0.0 & Cytoskeleton \\
W & 0 & 0.0 & Extracellular structures \\
U & 73 & 1.7 & Intracellular trafficking, secretion, and vesicular transport \\
O & 132 & 3.1 & Posttranslational modification, protein turnover, chaperones \\
C & 204 & 4.7 & Energy production and conversion \\
G & 351 & 8.1 & Carbohydrate transport and metabolism \\
E & 304 & 7.0 & Amino acid transport and metabolism \\
F & 86 & 2.0 & Nucleotide transport and metabolism \\
H & 161 & 3.7 & Coenzyme transport and metabolism \\
I & 158 & 3.7 & Lipid transport and metabolism \\
P & 226 & 5.2 & Inorganic ion transport and metabolism \\
Q & 99 & 2.3 & Secondary metabolites biosynthesis, transport and catabolism \\
R & 620 & 14.3 & General function prediction only \\
S & 372 & 8.6 & Function unknown \\
- & 2,113 & 35.1 & Not in COGs \\
\hline & & & \\
\hline
\end{tabular}

\section{Acknowledgements}

We would like to gratefully acknowledge the help of Regine Fähnrich (DSMZ) for growing R. slithyformis cultures. This work was performed under the auspices of the US Department of Energy Office of Science, Biological and Environmental Research Program, and by the University of California, Lawrence Berkeley National Laboratory under contract No. DE-AC02-05CH11231,
Lawrence Livermore National Laboratory under Contract No. DE-AC52-07NA27344, and Los Alamos National Laboratory under contract No. DE-AC0206NA25396, UT-Battelle and Oak Ridge National Laboratory under contract DE-AC05-000R22725, as well as German Research Foundation (DFG) INST 599/1-2.

\section{References}

1. Larkin JM, Williams PM. Runella slithyformis gen. nov., sp. nov., a curved, nonflexible, pink bacterium. Int / Syst Bacteriol 1978; 28:32-36. http://dx.doi.org/10.1099/00207713-28-1-32

2. Skerman VBD, McGowan V, Sneath PHA. Approved lists of bacterial names. Int / Syst Bacteriol

1980; 30:225-420.

http://dx.doi.org/10.1099/00207713-30-1-225

3. Euzéby JP. List of bacterial names with standing in nomenclature: a folder available on the Internet. Int J Syst Bacteriol 1997; 47:590-592. PubMed http://dx.doi.org/10.1099/00207713-47-2-590 
Copeland et al.

4. Lu S, Lee JR, Ryu SH, Chung BS, Choe WS, Jeon CO. Runella defluvii sp. nov., isolated from a domestic wastewater treatment plant. Int I Syst Evol Microbiol 2007; 57:2600-2603. PubMed http://dx.doi.org/10.1099/ijs.0.65252-0

5. Furuhata K, Kato Y, Goto K, Saitou K, Sugiyama J, Hara M, Fukuyama M. Identification of pinkpigmented bacteria isolated from environmental water samples and their biofilm fromation abilities. Biocontrol Sci 2008; 13:33-39. PubMed http://dx.doi.org/10.4265/bio.13.33

6. Ryu SH, Nguyen TTH, Park W, Kim CJ, Jeon CO. Runella limosa sp. nov., isolated from activated sludge. Int / Syst Evol Microbiol 2006; 56:27572760. PubMed http://dx.doi.org/10.1099/ijs.0.64460-0

7. Chelius MK, Henn JA, Triplett EW. Runella zeae sp. nov., a novel Gram-negative bacterium from the stems of surface-sterilized Zea mays. Int J Syst Evol Microbiol 2002; 52:2061-2063. PubMed http://dx.doi.org/10.1099/ijs.0.02203-0

8. Altschul SF, Gish W, Miller W, Myers EW, Lipman DJ. Basic local alignment search tool. J Mol Biol 1990; 215:403-410. PubMed

9. Korf I, Yandell M, Bedell J. BLAST, O'Reilly, Sebastopol, 2003.

10. DeSantis TZ, Hugenholtz $P$, Larsen N, Rojas $M$, Brodie EL, Keller K, Huber T, Dalevi D, Hu P, Andersen GL. Greengenes, a chimera-checked $16 \mathrm{~S}$ rRNA gene database and workbench compatible with ARB. Appl Environ Microbiol 2006; 72:50695072. PubMed http://dx.doi.org/10.1128/AEM.03006-05

11. Porter MF. An algorithm for suffix stripping. Program: electronic library and information systems. 1980; 14:130-137.

12. Castresana J. Selection of conserved blocks from multiple alignments for their use in phylogenetic analysis. Mol Biol Evol 2000; 17:540-552. PubMed http://dx.doi.org/10.1093/oxfordjournals.molbev.a $\underline{026334}$

13. Lee C, Grasso C, Sharlow MF. Multiple sequence alignment using partial order graphs. Bioinformatics 2002; 18:452-464. PubMed http://dx.doi.org/10.1093/bioinformatics/18.3.452

14. Stamatakis A, Hoover P, Rougemont J. A rapid bootstrap algorithm for the RAxML web-servers. Syst Biol 2008; 57:758-771. PubMed http://dx.doi.org/10.1080/10635150802429642

15. Hess PN, De Moraes Russo CA. An empirical test of the midpoint rooting method. Biol / Linn SoC
Lond 2007; 92:669-674.

http://dx.doi.org/10.1111/j.10958312.2007.00864.x

16. Pattengale ND, Alipour M, Bininda-Emonds ORP, Moret BME, Stamatakis A. How many bootstrap replicates are necessary? Lect Notes Comput Sci 2009; 5541:184-200. http://dx.doi.org/10.1007/978-3-642-02008-7_13

17. Swofford DL. PAUP*: Phylogenetic Analysis Using Parsimony (*and Other Methods), Version 4.0 b10. Sinauer Associates, Sunderland, 2002.

18. Liolios K, Chen IM, Mavromatis K, Tavernarakis N, Hugenholtz P, Markowitz VM, Kyrpides NC. The Genomes On Line Database (GOLD) in 2009: status of genomic and metagenomic projects and their associated metadata. Nucleic Acids Res 2010; 38:D346-D354. PubMed http://dx.doi.org/10.1093/nar/gkp848

19. Abt B, Teshima H, Lucas S, Lapidus A, Del Rio TG, Nolan M, Tice H, Cheng JF, Pitluck S, Liolios K, et al. Complete genome sequence of Leadbetterella byssophila type strain $\left(4 \mathrm{M} 15^{\top}\right)$. Stand Genomic Sci 2011; 4:2-12. PubMed http://dx.doi.org/10.4056/sigs.1413518

20. Lail K, Sikorski J, Saunders E, Lapidus A, Del Rio TG, Copeland A, Tice H, Cheng JF, Lucas S, Nolan $\mathrm{M}$, et al. Complete genome sequence of Spirosoma linguale type strain $\left(1^{\top}\right)$. Stand Genomic Sci 2010; 2:176-185. PubMed http://dx.doi.org/10.4056/sigs.741334

21. Lang E, Lapidus A, Chertkov O, Brettin T, Detter JC, Han C, Copeland A, Del Rio TG, Nolan M, Chen $\mathrm{F}$, et al. Complete genome sequence of Dyadobacter fermentans type strain (NS114 $\left.{ }^{\top}\right)$. Stand Genomic Sci 2009; 1:133-140. PubMed http://dx.doi.org/10.4056/sigs.19262

22. Xie G, Bruce DC, Challacombe JF, Chertkov O, Detter JC, Gilna P, Han CS, Lucas S, Misra M, Myers $\mathrm{GL}$, et al. Genome sequence of the cellulolytic gliding bacterium Cytophaga hutchinsonii. Appl Environ Microbiol 2007; 73:3536-3546. PubMed http://dx.doi.org/10.1128/AEM.00225-07

23. Chelius MK, Triplett EW. gen. nov., sp. nov., a novel Gram-negative bacterium isolated from surface-sterilized Zea mays stems. Int / Syst Evol Microbiol 2000; 50:751-758. PubMed http://dx.doi.org/10.1099/00207713-50-2-751

24. Field D, Garrity G, Gray T, Morrison N, Selengut J, Sterk P, Tatusova T, Thomson N, Allen MJ, Angiuoli SV, et al. The minimum information about a genome sequence (MIGS) specification. 
Nat Biotechnol 2008; 26:541-547. PubMed

http://dx.doi.org/10.1038/nbt1360

25. Woese CR, Kandler O, Wheelis ML. Towards a natural system of organisms: proposal for the domains, and Eucarya. Proc Natl Acad Sci USA 1990; 87:4576-4579. PubMed http://dx.doi.org/10.1073/pnas.87.12.4576

26. Krieg NR, Ludwig W, Euzéby J, Whitman WB. Phylum XIV. Bacteroidetes phyl. nov. In: Krieg NR, Staley JT, Brown DR, Hedlund BP, Paster BJ, Ward NL, Ludwig W, Whitman WB (eds), Bergey's Manual of Systematic Bacteriology, second edition, vol. 4 (The Bacteroidetes, Spirochaetes, Tenericutes (Mollicutes), Acidobacteria, Fibrobacteres, Fusobacteria, Dictyoglomi, Gemmatimonadetes, Lentisphaerae, Verrucomicrobia, Chlamydiae, and Planctomycetes), Springer, New York, 2010, p. 25.

27. List Editor. Validation List $\mathrm{N}^{\circ} 143$. Int / Syst Evol Microbiol 2012; 62:1-4. http://dx.doi.org/10.1099/ijs.0.039487-0

28. Nakagawa Y. Class IV. Cytophagia class. nov. In: Krieg NR, Staley JT, Brown DR, Hedlund BP, Paster BJ, Ward NL, Ludwig W, Whitman WB (eds), Bergey's Manual of Systematic Bacteriology, second edition, vol. 4 (The Bacteroidetes, Spirochaetes, Tenericutes (Mollicutes), Acidobacteria, Fibrobacteres, Fusobacteria, Dictyoglomi, Gemmatimonadetes, Lentisphaerae, Verrucomicrobia, Chlamydiae, and Planctomycetes), Springer, New York, 2010, p. 370.

29. Leadbetter ER. Order II. Cytophagales Nomen novum. In: Buchanan RE, Gibbons NE (eds), Bergey's Manual of Determinative Bacteriology, Eighth Edition, The Williams and Wilkins Co., Baltimore, 1974, p. 99.

30. Stanier RY. Studies on the Cytophagas. J Bacteriol 1940; 40:619-635. PubMed

31. Gemeinholzer B, Dröge $G$, Zetzsche $H$, Haszprunar G, Klenk HP, Güntsch A, Berendsohn WG, Wägele JW. The DNA Bank Network: the start from a German initiative. Biopreserv Biobank 2011; 9:51-55.

http://dx.doi.org/10.1089/bio.2010.0029

32. BAuA. 2010. Classification of bacteria and archaea in risk groups. TRBA 466, p. 194. www.baua.de Bundesanstalt für Arbeitsschutz und Arbeitsmedizin, Germany.

33. Ashburner M, Ball CA, Blake JA, Botstein D, Butler $\mathrm{H}$, Cherry JM, Davis AP, Dolinski K, Dwight SS, Eppig JT, et al. Gene Ontology: tool for the unifica- tion of biology. Nat Genet 2000; 25:25-29. Pub-

Med http://dx.doi.org/10.1038/75556

34. Klenk HP, Göker M. En route to a genome-based classification of and? Syst App/ Microbiol 2010; 33:175-182. PubMed http://dx.doi.org/10.1016/j.syapm.2010.03.003

35. Wu D, Hugenholtz P, Mavromatis K, Pukall R, Dalin E, Ivanova NN, Kunin V, Goodwin L, Wu M, Tindall BJ, et al. A phylogeny-driven genomic encyclopaedia of and. Nature 2009; 462:1056-1060. PubMed http://dx.doi.org/10.1038/nature08656

36. List of growth media used at DSMZ: http://www.dsmz.de/catalogues/cataloguemicroorganisms/culture-technology/list-of-mediafor-microorganisms.html.

37. JGI website. http://www.jgi.doe.gov

38. The Phred/Phrap/Consed software package. http://www.phrap.com

39. Zerbino DR, Birney E. Velvet: algorithms for de novo short read assembly using de Bruijn graphs. Genome Res 2008; 18:821-829. PubMed http://dx.doi.org/10.1101/gr.074492.107

40. Han C, Chain P. Finishing repeat regions automatically with Dupfinisher. In: Proceeding of the 2006 international conference on bioinformatics \& computational biology. Arabnia HR, Valafar H (eds), CSREA Press. June 26-29, 2006: 141-146.

41. Lapidus A, LaButti K, Foster B, Lowry S, Trong S, Goltsman E. POLISHER: An effective tool for using ultra short reads in microbial genome assembly and finishing. AGBT, Marco Island, FL, 200845. J Bacteriol 1940; 40:619-635.

42. Hyatt D, Chen GL, LoCascio PF, Land ML, Larimer FW, Hauser LJ. Prodigal: prokaryotic gene recognition and translation initiation site identification. BMC Bioinformatics 2010; 11:119. PubMed http://dx.doi.org/10.1186/1471-2105-11-119

43. Pati A, Ivanova NN, Mikhailova N, Ovchinnikova G, Hooper SD, Lykidis A, Kyrpides NC.

GenePRIMP: a gene prediction improvement pipeline for prokaryotic genomes. Nat Methods 2010; 7:455-457. PubMed http://dx.doi.org/10.1038/nmeth.1457

44. Markowitz VM, Ivanova NN, Chen IMA, Chu K, Kyrpides NC. IMG ER: a system for microbial genome annotation expert review and curation. Bioinformatics 2009; 25:2271-2278. PubMed http://dx.doi.org/10.1093/bioinformatics/btp393 